\title{
Neuronal Correlates of Amblyopia in the Visual Cortex of Macaque Monkeys with Experimental Strabismus and Anisometropia
}

\author{
Lynne Kiorpes, ${ }^{1}$ Daniel C. Kiper, ${ }^{2}$ Lawrence P. O’Keefe, ${ }^{1}$ James R. Cavanaugh, ${ }^{1}$ and J. Anthony Movshon ${ }^{2}$ \\ ${ }^{1}$ Center for Neural Science and ${ }^{2}$ Howard Hughes Medical Institute, New York University, New York, New York 10003
}

Amblyopia is a developmental disorder of pattern vision. After surgical creation of esotropic strabismus in the first weeks of life or after wearing -10 diopter contact lenses in one eye to simulate anisometropia during the first months of life, macaques often develop amblyopia. We studied the response properties of visual cortex neurons in six amblyopic macaques; three monkeys were anisometropic, and three were strabismic.

In all monkeys, cortical binocularity was reduced. In anisometropes, the amblyopic eye influenced a relatively small proportion of cortical neurons; in strabismics, the influence of the two eyes was more nearly equal. The severity of amblyopia was related to the relative strength of the input of the amblyopic eye to the cortex only for the more seriously affected amblyopes.

Measurements of the spatial frequency tuning and contrast sensitivity of cortical neurons showed few differences between the eyes for the three less severe amblyopes (two strabismic and one anisometropic). In the three more severely affected animals (one strabismic and two anisometropic), the optimal spatial frequency and spatial resolution of cortical neurons driven by the amblyopic eye were substantially and significantly lower than for neurons driven by the nonamblyopic eye. There were no reliable differences in neuronal contrast sensitivity between the eyes. A sample of neurons recorded from cortex representing the peripheral visual field showed no interocular differences, suggesting that the effects of amblyopia were more pronounced in portions of the cortex subserving foveal vision.

Qualitatively, abnormalities in both the eye dominance and spatial properties of visual cortex neurons were related on a case-by-case basis to the depth of amblyopia. Quantitative analysis suggests, however, that these abnormalities alone do not explain the full range of visual deficits in amblyopia. Studies of extrastriate cortical areas may uncover further abnormalities that explain these deficits.

Key words: visual development; visual cortex; amblyopia; anisometropia; strabismus; macaque monkeys
Visual function in adulthood depends on an individual's visual experience in infancy. The work of Wiesel and Hubel (1963, 1965) established that the first stage of visual processing affected by visual experience is in the primary visual cortex, and a large body of subsequent work has shown that various forms of anomalous visual experience modify the development of the functional properties and architecture of cortical neurons (for review, see Movshon and Van Sluyters, 1981; Movshon and Kiorpes, 1990). It is no surprise that changes in visual cortical function are associated with changes in visual performance assessed in behavioral tasks (for review, see Kiorpes and Movshon, 1990).

Following Wiesel and Hubel, most work on the effect of visual experience on development has concentrated on the effects of complete or partial deprivation of visual input, which leads to more or less wholesale loss of effective inputs from the deprived eye to neurons in the visual cortex. Such deprivation is rare in

\footnotetext{
Received March 18, 1998; revised June 3, 1998; accepted June 5, 1998.

This research was supported by National Institutes of Health Grants EY05864, EY02017, and RR00166, and by an investigatorship to J.A.M. from the Howard Hughes Medical Institute. D.C.K. was supported in part by a fellowship from the Fonds National Suisse pour la Recherche. Michael Hawken and Chao Tang participated in some of these experiments. We thank Suzanne Fenstemaker, Jasmine Allen Siegel, Michael Gorman, and Patricia Adler for their assistance, and Drs. Howard Eggers and Melvin Carlson for their expert strabismus surgery.

Correspondence should be addressed to Lynne Kiorpes, Center for Neural Science, New York University, 4 Washington Place, Room 809, New York, NY 10003.

Dr. Kiper's present address: Institut de Biologie Cellulaire et Morphologie, Faculté de Medecine, Université de Lausanne, CH-1015 Lausanne, Switzerland Copyright (ㄷ) 1998 Society for Neuroscience $0270-6474 / 98 / 186411-14 \$ 05.00 / 0$
}

humans, who more commonly experience abnormal early vision as a result of either strabismus (a misalignment of the visual axes that prevents concordant stimulation of binocularly corresponding points in the two retinas) or anisometropia (a difference in refractive state between the eyes that leads one retinal image always to be blurred). These two conditions are strongly associated with the development of amblyopia, a reduction in visual acuity without an obvious organic cause. Amblyopia is characterized by a constellation of deficits in spatial vision, as indexed by visual acuity, spatial contrast sensitivity, and other tasks (for review, see Von Noorden, 1980; Levi and Carkeet, 1993). Some reports on humans suggest that anisometropia and strabismus lead to different forms of amblyopia, although this is by no means a universal finding (Hess et al., 1978; Levi and Klein, 1982; McKee et al., 1992; Movshon et al., 1996). In recent years, we and others have studied the characteristics of amblyopia in macaque monkeys raised with artificially created forms of strabismus and anisometropia. Psychophysical studies show that the amblyopia that follows this rearing closely resembles the condition described in humans (Harwerth et al., 1983; Smith et al., 1985; Kiorpes et al., 1987; 1989; Kiorpes and Movshon, 1996).

The neural basis of amblyopia has been less thoroughly explored. Changes in the degree of binocular interaction have been documented in amblyopic monkeys (e.g., Movshon et al., 1987; Crawford et al., 1996; Smith et al., 1997), but it seems unlikely that changes in binocular interaction alone can explain the abnormalities of amblyopic vision. There is also a substantial, although inconsistent, literature on developmental visual abnormalities in cats, but this literature is of uncertain value for 
Table 1. The experimental subjects, treatment histories, psychophysical and physiological parameters, and significance of differences

\begin{tabular}{|c|c|c|c|c|c|c|c|c|c|c|c|c|c|}
\hline \multirow[b]{2}{*}{ Monkey } & \multirow[b]{2}{*}{ Eye } & \multirow[b]{2}{*}{ Treatment } & \multirow[b]{2}{*}{$\begin{array}{l}\text { Age at } \\
\text { onset (d) }\end{array}$} & \multicolumn{4}{|c|}{ Psychophysics } & \multicolumn{6}{|c|}{ Physiology (geometric means) } \\
\hline & & & & $\begin{array}{l}\text { Amblyopia } \\
\text { index }\end{array}$ & $\begin{array}{l}\text { Peak } \\
\text { contrast } \\
\text { sensitivity }\end{array}$ & $\begin{array}{l}\text { Best } \\
\text { spatial } \\
\text { frequency }\end{array}$ & $\begin{array}{l}\text { Spatial } \\
\text { resolution }\end{array}$ & $\begin{array}{l}\text { Peak } \\
\text { contrast } \\
\text { sensitivity }\end{array}$ & & $\begin{array}{l}\text { Best } \\
\text { spatial } \\
\text { frequency }\end{array}$ & & $\begin{array}{l}\text { Spatial } \\
\text { resolution }\end{array}$ & \\
\hline \multirow{2}{*}{$\mathrm{GH}$} & $\mathrm{L}$ & Esotropia & \multirow{2}{*}{45} & \multirow{2}{*}{0.444} & 36.6 & 3.22 & 18.6 & 10.05 & \multirow{2}{*}{$*$} & 1.91 & \multirow{2}{*}{ NS } & 5.53 & \multirow{2}{*}{ NS } \\
\hline & $\mathrm{R}$ & None & & & 58.4 & 4.37 & 29.6 & 7.52 & & 1.48 & & 4.66 & \\
\hline \multirow{2}{*}{$\mathrm{HC}$} & $\mathrm{L}$ & Esotropia & \multirow{2}{*}{86} & \multirow{2}{*}{0.624} & 12.3 & 2.14 & 11.9 & 8.91 & \multirow{2}{*}{ NS } & 1.64 & \multirow{2}{*}{ NS } & 4.11 & \multirow{2}{*}{ NS } \\
\hline & $\mathrm{R}$ & None & & & 26.9 & 4.18 & 23.8 & 6.28 & & 1.85 & & 4.88 & \\
\hline \multirow{2}{*}{ FT } & $\mathrm{L}$ & Esotropia & \multirow{2}{*}{22} & \multirow{2}{*}{0.732} & 35.2 & 1.67 & 6.61 & 8.97 & \multirow{2}{*}{ NS } & 1.13 & \multirow[t]{2}{*}{$* *$} & 3.32 & \multirow[t]{2}{*}{$* *$} \\
\hline & $\mathrm{R}$ & None & & & 61.4 & 3.56 & 21.4 & 9.82 & & 1.80 & & 6.62 & \\
\hline \multirow{2}{*}{ LF } & $\mathrm{L}$ & 0 lens & \multirow{2}{*}{10} & \multirow{2}{*}{0.651} & 43.2 & 1.91 & 11.7 & 10.76 & \multirow[t]{2}{*}{$*$} & 2.29 & \multirow{2}{*}{ NS } & 7.16 & \multirow{2}{*}{ NS } \\
\hline & $\mathrm{R}$ & -10 lens & & & 23.0 & 1.12 & 4.92 & 6.53 & & 1.66 & & 5.85 & \\
\hline \multirow{2}{*}{ FP } & $\mathrm{L}$ & 0 lens & \multirow{2}{*}{19} & \multirow{2}{*}{0.663} & 55.1 & 3.64 & 22.4 & 11.56 & \multirow{2}{*}{ NS } & 1.97 & \multirow[t]{2}{*}{$* *$} & 5.32 & $* *$ \\
\hline & $\mathrm{R}$ & -10 lens & & & 27.7 & 1.98 & 9.1 & 10.89 & & 1.03 & & 3.20 & \\
\hline $\mathrm{OC}$ & $\mathrm{L}$ & 0 lens & 25 & 0.904 & 135.0 & 2.78 & 21.4 & 9.73 & NS & 2.89 & $* *$ & 7.60 & $* *$ \\
\hline . & $\mathrm{R}$ & -10 lens & 20 & (0.50 & 26.3 & 0.72 & 3.04 & 8.49 & 175 & 1.79 & & 5.13 & \\
\hline
\end{tabular}

${ }^{*} p<0.01, t$ test; ${ }^{* *} p<0.001, t$ test.

NS, $p>0.01, t$ test.

understanding amblyopia, because it is not clear that cats develop the condition as primates do (for review, see Movshon and Kiorpes, 1990; Daw, 1995).

We have shown previously that the amblyopia that follows one particular form of abnormal early experience, unilateral blur created by atropine instillation, is associated with a pattern of physiological and anatomical changes in visual cortex quite different from that seen following monocular deprivation. Instead of a wholesale loss of input, we found changes in the function and architecture of the visual cortex that were more subtle, suggesting a selective rearrangement, but not a complete loss, of effective inputs from the amblyopic eye (Hendrickson et al., 1987; Movshon et al., 1987).

The interpretation of these results is complicated, because unilateral atropine instillation is a relatively uncontrolled technique for modifying early visual experience. We have therefore raised and studied two new groups of experimentally amblyopic monkeys. To simulate strabismus, we misaligned the visual axes by surgical modification of the extraocular muscles. To simulate anisometropia, we used extended-wear contact lenses with different powers in the two eyes. Just as humans vary in their response to early visual abnormalities, so do monkeys. In this paper, we report the effects of these two rearing regimens in a selected group of animals in whom the rearing created a relatively modest visual loss in the amblyopic eye. Our results show that this amblyopia is usually associated with deleterious changes in the spatial properties of neurons driven by the amblyopic eye in the visual cortex, and in some cases, also with a loss of effective inputs from the amblyopic eye. These changes are associated, on an animal-by-animal basis, with the depth of amblyopia. We did not observe distinctively different results in neuronal properties or visual behavior between the strabismic and anisometropic animals. Quantitatively, the changes in cortical neuron properties are smaller than those seen behaviorally, suggesting that the neural basis of amblyopia begins, but does not end, in the primary visual cortex.

In addition to previous publications of some of the behavioral data (specifically noted below), a brief report of some of these physiological results has appeared previously (Kiorpes and Movshon, 1996).

\section{MATERIALS AND METHODS}

Subjects. Six amblyopic pig-tailed macaques, Macaca nemestrina, were used in this study. They were hand-raised from infancy in our primate nursery or in the nursery of the Washington Regional Primate Center, where they were born. Three monkeys were raised with unilateral esotropia, and three were raised with unilateral defocus. These six animals were selected for this study from larger groups of strabismic and anisometropic animals on the basis of their degree of amblyopia. Data from three other strabismic monkeys that belong to another study (Fenstemaker et al., 1997) are briefly presented in Figure 3. Control data were obtained from eight monkeys raised normally. Care of the animals was provided in accordance with established approved protocols, which conform to the NIH Guide for the Care and Use of Laboratory Animals. Experimental histories for the monkeys are presented in Table 1, in which onset age corresponds to the age at which the experimental condition was begun. Refractive data from some of these animals have been presented elsewhere (Kiorpes et al., 1989; Kiorpes and Wallman, 1995).

Experimental strabismus. Esotropia was induced by transection of the lateral rectus muscle and resection of the medial rectus muscle of the left eye. The medial rectus was, in addition, advanced to the limbus. Surgery was performed under ketamine-hydrochloride sedation using sterile surgical techniques. The resulting esotropia was typically moderate, ranging from 10 to 25 prism diopters estimated by the Hirschberg method from photographs; this method is accurate to 5 prism diopters (see Kiorpes et al., 1989).

Experimental anisometropia. Anisometropia was simulated by inserting a -10 diopter extended-wear soft contact lens in the right eye and inserting a zero-power lens in the left (Kiorpes et al., 1993). The monkey wore the lenses beginning $10-25 \mathrm{~d}$ after birth for $7-10$ months. The status and condition of the lenses were checked frequently through each day; missing lenses were infrequent and were replaced immediately. The lenses were routinely changed and cleaned weekly. Regular ophthalmic examinations were performed to ensure the health of the eyes. Eye alignment was evaluated casually by inspection daily and by the Hirschberg method twice during rearing. No strabismus was obvious during the rearing period in any of the lens-reared animals; however, we would not have detected a tropia or phoria of $<5$ prism diopters. One animal (monkey LF) developed a large exotropia following the rearing period.

\section{Behavioral testing}

The animals were trained to perform an operant two-alternative forcedchoice discrimination task. Our training and testing procedures used have been detailed previously (Williams et al., 1981; Kiorpes, 1992a; Kiorpes et al., 1993). The animals were placed in a testing cage from which they viewed the stimuli and responded by pulling one of two grab bars located within their reach. The monkeys were rewarded with $0.25 \mathrm{cc}$ of apple juice for correct discriminations; errors were followed by a 
time-out period, usually $5-10 \mathrm{sec}$ in duration, that was signaled by a tone. Each eye was tested independently for each animal. Optical correction was provided as needed based on behaviorally established best refraction (Kiorpes and Boothe, 1984). The animals were all visually mature at the time the measurements reported in this paper were made; age at test ranged from 1 to 7 years. We began operant visual assessments between 6 months and 1 year; in some cases, testing on a variety of visual spatial tasks detailed elsewhere continued for many years thereafter (for additional behavioral data, see Kiorpes et al., 1989, 1993; Kiper, 1994; Kiper and Kiorpes, 1994; Kiper et al., 1995).

To measure spatial contrast sensitivity, sinusoidal gratings were generated under computer control on one of two types of display systems. One system consisted of a pair of Joyce Electronics DM-2 displays (white phosphor) controlled by a PDP-11 computer. The luminance of the displays was $250 \mathrm{~cd} / \mathrm{m}^{2}$. Each screen was visible through a circular aperture that subtended $6-12^{\circ}$ depending on the viewing distance, which ranged from 0.9 to $1.8 \mathrm{~m}$ depending on the animal's visual acuity. The other system consisted of a Mitsubishi Diamondscan HL6605 (mean luminance, $60 \mathrm{~cd} / \mathrm{m}^{2}$ ) controlled by a personal computer with a Vista graphics board (True Vision, Inc.). The monitor screen subtended $12-40^{\circ}$ depending on the viewing distance, which ranged from 0.5 to $2 \mathrm{~m}$. The stimuli in this case were patches of sinusoidal grating vignetted by a two-dimensional spatial Gaussian $\left(\sigma\right.$ value, $0.75^{\circ}$, except for very low spatial frequencies in which $\sigma$ was increased to keep at least three grating cycles visible).

The animal's task was to discriminate the grating from a homogeneous field matched in space-average luminance; the stimuli were displayed steadily for as long as the animal wished on any given trial. For most contrast sensitivity functions, five contrast values for each of four to six spatial frequencies were presented in pseudorandom order. Each contrast sensitivity estimate is based on at least 40 trials per stimulus condition. Threshold was defined as the contrast-supporting discrimination by the subject at the $75 \%$ correct level. Threshold values and SEs of estimate were obtained by probit analysis of the log transformed data sets (Finney, 1971) using a maximum likelihood fitting technique.

\section{Electrophysiological recording}

Surgical preparation and maintenance. Animals were prepared for acute single-unit recording using methods we have described in detail elsewhere (Levitt et al., 1994); age at recording ranged from 8 to 11 years. They were premedicated with atropine $(0.25 \mathrm{mg})$ and acepromazine $(0.05 \mathrm{mg} / \mathrm{kg}$ ) or diazepam (Valium; $0.5 \mathrm{mg} / \mathrm{kg})$. After induction of anesthesia with intramuscular injections of ketamine $\mathrm{HCl}$ (Vetalar; $10-30 \mathrm{mg} / \mathrm{kg}$ ), cannulas were inserted into the trachea and the saphenous veins, the animal's head was fixed in a stereotaxic frame, and surgery was completed under intravenous anesthesia with sufentanil citrate (Sufenta; $4-8 \mu \mathrm{g} / \mathrm{kg} / \mathrm{hr}$ ). Infusion of the surgical anesthetic continued throughout the recordings.

To minimize eye movements during recording, paralysis was maintained with an infusion of pancuronium bromide (Pavulon; $0.1 \mathrm{mg} / \mathrm{kg}$ / $\mathrm{hr}$ ) or vecuronium bromide (Norcuron; $0.1 \mathrm{mg} / \mathrm{kg} / \mathrm{hr}$ ) in lactated Ringer's solution with dextrose $(5-20 \mathrm{ml} / \mathrm{hr})$. Animals were artificially ventilated with room air or a mixture of $50-70 \% \mathrm{~N}_{2} \mathrm{O}$ in $\mathrm{O}_{2}$. Peakexpired $\mathrm{CO}_{2}$ was maintained near $4 \%$ by adjusting the tidal volume of the ventilator. Rectal temperature was kept near $37^{\circ} \mathrm{C}$ with a thermostatically controlled heating pad. Animals received daily injections of a broad-spectrum antibiotic (Bicillin; 300,000 units) to prevent infection, as well as dexamethasone (Decadron; $0.5 \mathrm{mg} / \mathrm{kg}$ ) to prevent cerebral edema. Electrocardiogram, EEG, autonomic signs, and rectal temperature were monitored continuously to ensure the adequacy of anesthesia and the soundness of the animal's physiological condition.

Physiological optics. The pupils were dilated and accommodation was paralyzed with topical atropine, and the corneas were protected with +2 diopter gas-permeable hard contact lenses. When necessary, supplementary lenses were chosen by direct ophthalmoscopy to make the retinas conjugate with the display screen. The power of the lenses was then adjusted as necessary to optimize the visual responses of recorded units. At least once a day, the locations of the foveas were recorded using a reversible ophthalmoscope.

Recording. Tungsten-in-glass microelectrodes (Merrill and Ainsworth, 1972) were introduced vertically by a hydraulic microdrive into the primary visual cortex through a small craniotomy and durotomy. Electrodes were angled tangentially to the cortical surface to sample from several eye-dominance columns. Most recordings were made from the foveal portion of $\mathrm{V} 1$. In one animal, additional recordings were made from portions of $\mathrm{V} 1$ representing the peripheral visual field $15-25^{\circ}$ from the fovea. In a second animal, additional recordings were made from foveal portions of V2. After the electrode was in place in the cortex, the exposed dura was covered with warm agar. Action potentials were conventionally amplified, displayed, and played over an audiomonitor.

To provide reasonably even and unbiased sampling of the distribution of cortical neuron properties, we used methods adapted from those of Stryker and Sherk (1975). After recording a neuron, we moved the electrode at least $50 \mu \mathrm{m}$ before accepting another unit for analysis. If we failed to isolate a unit within $100 \mu \mathrm{m}$ of the previous recording site, we recorded the properties of the unresolved multiunit background activity; this was necessary at between $5 \%$ and $10 \%$ of the recording sites in each experiment.

Characterization of receptive fields. We initially mapped receptive fields by hand on a tangent screen using black and white geometric targets. We drew the location and size of the minimum response fields of the neuron and determined its selectivity for the orientation, direction of motion, and size of stimuli. Ocular dominance was assessed qualitatively using the seven-point scale of Hubel and Wiesel (1962). Units were classified as ocular dominance group 4 if we could not distinguish any difference between the responses to stimulation of the two eyes. They were classified as groups 3 or 5 if they responded well to both eyes but with a discernible preference for the contralateral or ipsilateral eye, respectively, classified as groups 2 or 6 if they responded predominantly to the contralateral or ipsilateral eye with a weak response to the other eye, and classified as groups 1 or 7 if they responded only to the contralateral or ipsilateral eye.

We then used a mirror to place the receptive field of the preferred eye on the face of a display monitor (Barco 7351 or Nanao T560i; frame rate, $107 \mathrm{~Hz}$ ) that subtended $10^{\circ}$ at the animal's eye; for some strongly binocular units, we studied the two eyes separately. Achromatic sinusoidal gratings with a mean luminance between 40 and $80 \mathrm{~cd} / \mathrm{m}^{2}$ were generated on this display by a computer. For most neurons, we determined neuronal selectivity for the orientation, direction, spatial frequency, temporal frequency, and contrast of continuously presented drifting gratings by adjusting these parameters while listening to the discharge over the audiomonitor. This gave estimates of the preferred orientation and direction, the bandwidth of orientation selectivity, the preferred and high-cutoff spatial frequency, and the preferred and highcutoff temporal frequency; we also estimated contrast threshold using targets optimized for the other parameters. For approximately one-fifth of the neurons, we also assessed these tuning parameters quantitatively using methods described elsewhere (Levitt et al., 1994).

Reconstruction of recording sites. During recording, small electrolytic lesions were produced at locations of interest along the electrode tracks by passing DC current ( $2 \mu \mathrm{A}$ for $2-5 \mathrm{sec}$, tip negative) through the electrode. At the end of the experiment, the animals were killed with an overdose of Nembutal and perfused through the heart with 21 of $0.1 \mathrm{M}$ PBS, followed by 21 of a solution containing $4 \%$ paraformaldehyde in 0.1 M PBS. The first liter of the fixative contained $4 \%$ sucrose, and the second liter had $12 \%$ sucrose added. Blocks containing the region of interest were stored overnight in the cold in a post-fix solution of $4 \%$ paraformaldehyde plus $30 \%$ sucrose, after which $40-\mu \mathrm{m}$-thick sections were cut on a freezing microtome. Sections were stained for Nissl substance with cresyl violet. In most cases, we were able to reconstruct the course of the electrode penetration with sufficient confidence to assign the recorded units to either the supragranular, granular, or infragranular layers of the cortex.

\section{RESULTS}

\section{Psychophysical observations}

Figure 1 shows spatial contrast sensitivity functions for a normal monkey (Fig. 1A) and for the six experimental monkeys (Fig. $1 B, C)$. The data for each eye are well described by the doubleexponential function

$$
S_{\omega}=a \omega^{b} e^{-c \omega}
$$

in which $\omega$ is spatial frequency, $S_{\omega}$ is contrast sensitivity, and $a, b$, and $c$ are fitted parameters. In the normal monkey, contrast sensitivity was very similar in the two eyes. In the amblyopic monkeys, both contrast sensitivity (the peak height of the func- 


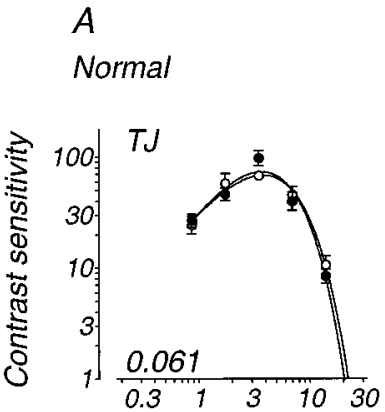

$B$

Strabismic
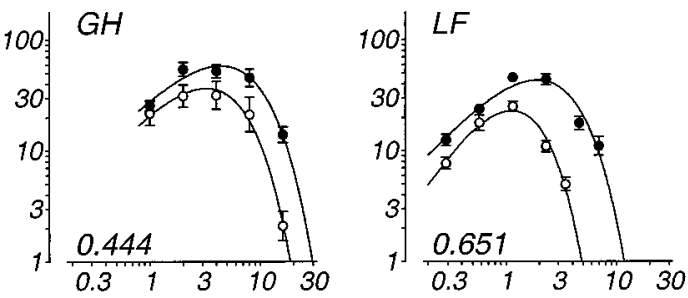

Figure 1. Spatial contrast sensitivity functions for a normally reared control monkey $(A)$ and for six amblyopic monkeys $(B, C)$. In each panel, data from the nonamblyopic eye are represented by filled symbols, and data from the amblyopic eye are represented by open symbols. The smooth curves represent the function described in the text; these curves were used to estimate the optimal spatial frequency, peak contrast sensitivity, and spatial resolution (the spatial frequency at which extrapolated sensitivity falls to 1). The number at the bottom left of each panel is the value of an amblyopia index, calculated by taking the area between the two fitted functions (plotted on linear frequency and logarithmic sensitivity coordinates) and dividing it by the area under the function for the nonamblyopic eye. The data shown for LF and $\mathrm{OC}$ were collected at a luminance of $250 \mathrm{~cd} / \mathrm{m}^{2}$; the other data were collected at $60 \mathrm{~cd} / \mathrm{m}^{2}$.

tion) and spatial scale (its position on the abscissa) were reduced. Table 1 shows the values of peak contrast sensitivity and of the spatial frequency at which the peak occurred, as well as the spatial resolution deduced from the high-frequency intercept of the function with a sensitivity of 1 . We also calculated a dimensionless amblyopia index by taking the area between the fitted contrast sensitivity function for the treated eye and the function for the untreated eye and dividing it by the area under the function for the untreated eye; this index ranges from 0 (no deficit) to 1 (no measurable sensitivity in the treated eye) and captures losses in both contrast sensitivity and spatial resolution. The value of the index for each monkey is printed at the bottom left of each panel in Figure 1. The severity of the amblyopia for the experimental monkeys varied somewhat from animal to animal but fell within the range that we and others have reported (Harwerth et al., 1983; Smith et al., 1985; Kiorpes, 1992b). Within Figure 1, $B$ and $C$, the animals are shown in order of the severity of their amblyopia at the most recent test age. Figure 2 plots the severity of amblyopia as the amblyopia index for each of these monkeys at all ages for which we have data. Filled symbols in Figure 2 indicate strabismic monkeys, open symbols indicate anisometropic monkeys, and solid lines connect repeated measures for the same monkey. The extent of amblyopia in this group was relatively stable over time despite variations in test stimuli and luminance; this is consistent with our data in other amblyopic animals. Note that monkeys GH, HC, FT, and FP were tested extensively between the initial and final contrast sensitivity measurement, suggesting that concentrated psychophysical experience does not diminish the amblyopia. Figure 2 also indicates the age at recording for each animal. The
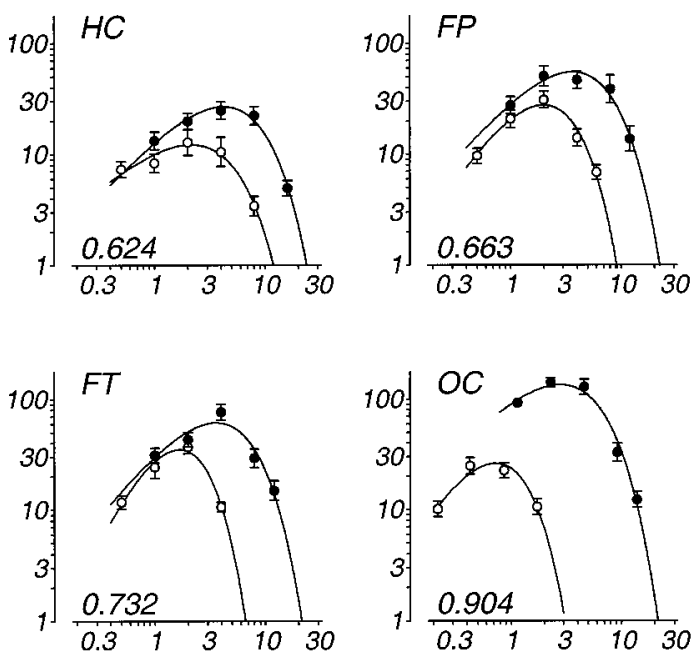

Spatial frequency (c/deg)

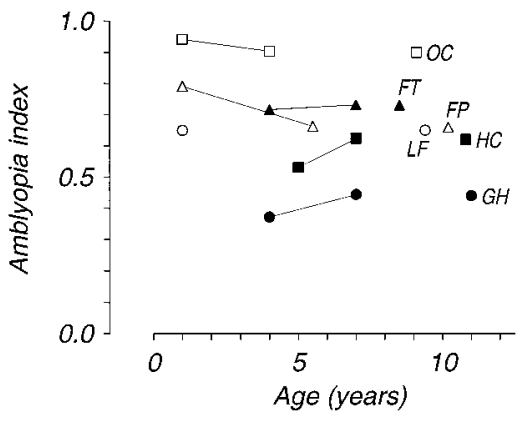

Figure 2. Amblyopia index as a function of age for the six amblyopic monkeys. Each monkey is represented by a different symbol (filled, strabismics; open, anisometropes); points connected by solid lines are repeated measures for the same monkey. Isolated points on the right show the age at recording for each animal; the amblyopia indices for these points are those shown in Figure 1, which are from the age closest to recording.

isolated symbols to the right of Figure 2 are plotted at the recording age; the $y$-axis positions for these points are the amblyopia index values from Figure 1.

The ranges of severity of amblyopia for the two treatment groups overlap, although the anisometropic subjects were on average more severely affected than the strabismics. The two least amblyopic animals were both strabismic ( $\mathrm{GH}$ and $\mathrm{HC})$; the most amblyopic animal was anisometropic (OC). In other cases, we 


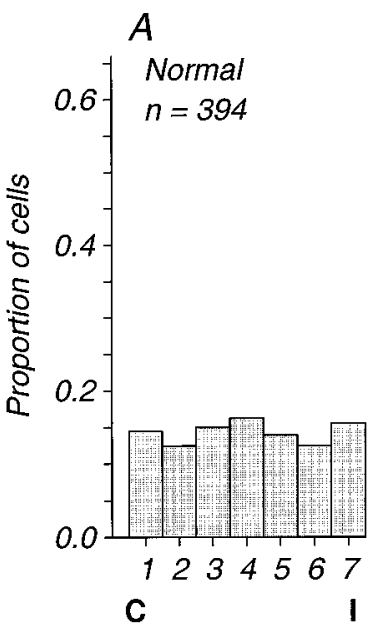

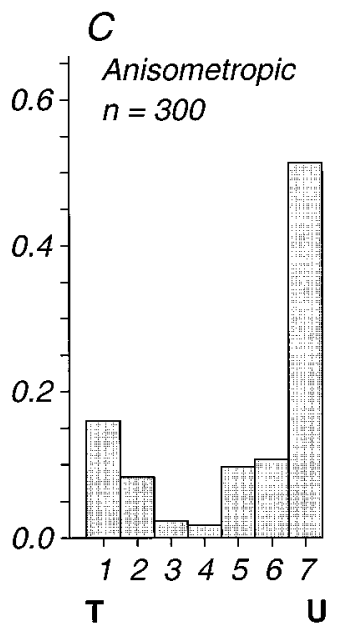

Eye dominance

$B$
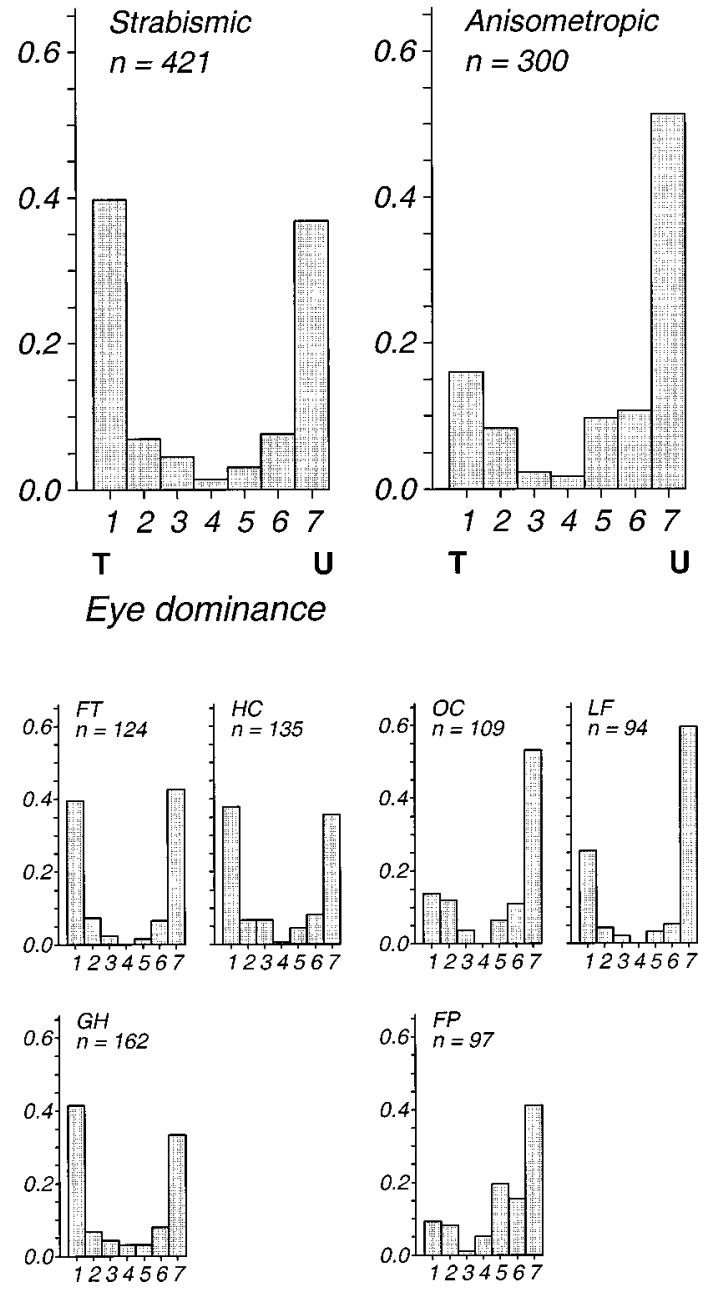

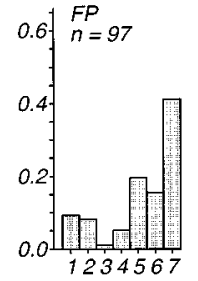

Figure 3. Distributions of cortical eye dominance from eight control monkeys $(A)$ and from the six amblyopic monkeys $(B, C)$. Eye dominance is represented using the seven-point scale of Hubel and Wiesel (1962). For the control monkeys, group 1 represents dominance by the contralateral eye $(C)$, and group 7 represents dominance by the ipsilateral eye $(I)$. For the amblyopic monkeys, data collected from the two hemispheres are combined so that group 1 represents dominance by the treated eye $(T)$ and group 7 represents dominance by the untreated eye $(U)$. The top histograms in $B$ and $C$ show distributions pooled across the three monkeys in each group; the bottom small histograms show the individuals' data. Only neurons with receptive fields representing the central visual fields are included; 76 units recorded from the representation of the peripheral visual field in monkey FT are excluded. In monkey FP, 35 units recorded in V2 are included; these were statistically indistinguishable from 62 other units recorded in V1. All other recordings were from V1. have observed a wide range of severity in the amblyopia that develops following strabismus or anisometropia, so these data do not represent the full range of effects seen (Kiorpes, 1992b; Kiorpes et al., 1993). Because of this wide variation in response to similar rearing treatments, we elected to include in this study only those animals showing a reliable amblyopic deficit that was not so profound that the animals were unable to perform all of our routine psychophysical tasks. We have briefly reported elsewhere on some cortical data from a group of more severely affected strabismic animals (Fenstemaker et al., 1997); the relevant portions of this data set will be discussed briefly below.

\section{Neurophysiological observations}

We studied the responses of 751 isolated neurons and 46 multiunit sites in the six experimental monkeys. In the strabismic animals, we made recordings in both hemispheres of each animal; in the anisometropic animals, we recorded only in the hemisphere contralateral to the treated eye. Because there were no important differences between data obtained from the two hemispheres, we have pooled the results.

In general, cortical activity was brisk and reliable, with most units responding well and exhibiting approximately normal degrees of stimulus selectivity. The majority of our recordings were made from the supragranular layers of the cortex, but we did not notice any particular tendency for units in any layer to be different in their response to strabismus or anisometropia.

\section{Eye dominance}

In agreement with previous reports (e.g., Crawford and Von Noorden, 1979; Wiesel, 1982), we found that strabismus virtually eliminated excitatory binocular convergence onto visual cortical neurons. Perhaps unexpectedly, binocularity was also sharply reduced by anisometropia. Figure 3 shows eye-dominance distributions for a control group of eight normal monkeys (Fig. $3 A$ ), for the strabismic and anisometropic monkeys (Fig. $3 B, C$ ), and for the six animals individually. When recordings were obtained from both hemispheres, they have been flipped, combined, and presented as though all recordings were made from the hemisphere contralateral to the treated eye; in Figure 3, $T$ and $U$ indicate the treated and untreated eyes, respectively.

In all the amblyopic monkeys, units were very sharply divided into clusters, $0.5-1 \mathrm{~mm}$ in extent, that were strongly dominated by one eye or the other. These clusters are presumably the physiological manifestations of the very distinct anatomical oculardominance columns seen in strabismic animals. These clusters were also strongly apparent in recordings made inadvertently from V2 in one monkey. In a number of cases, we noticed narrow zones, 50-100 $\mu \mathrm{m}$ wide, at the borders of these eye-dominance clusters in which units were difficult to isolate or to drive visually. We suspect that these transition zones, which in normal monkeys contain the most strongly binocular units, are particularly affected when cortical binocularity is lost; we have also reported anatom- 
ical evidence for abnormalities in the border regions of oculardominance columns in strabismic monkeys (Fenstemaker et al., 1994, 1997).

In normal monkeys, our results on the overall distribution of eye dominance are in general agreement with previous reports (e.g., Hubel and Wiesel, 1968), although in our hands binocular neurons were somewhat more common. Most neurons (70\%) were binocularly activated, and $85 \%$ responded to some degree to stimulation of one eye or the other.

In all of the amblyopic monkeys, cortical binocularity was sharply reduced. The proportion of binocularly activated units in the three strabismic monkeys ranged from 18 to $27 \%$; in the anisometropes, the range was from 15 to $50 \%$. It is noteworthy that the anisometropic monkey with the smallest number of binocularly activated units (LF) had developed an exotropic strabismus after the end of the lens-rearing period.

In the three strabismic monkeys, eye dominance was approximately evenly balanced, with the amblyopic eye dominating between 49 and $54 \%$ of the units. In the three anisometropes, the amblyopic eye dominated a smaller fraction of neurons (21-32\%), suggesting that this eye had suffered a competitive disadvantage in its effectiveness in driving cortical neurons. The lack of an eye-dominance shift in the strabismics was characteristic only of this group of relatively mild strabismic amblyopes. Other strabismics with more profound amblyopia often show eye-dominance shifts as great or greater than those seen in this group of anisometropes (see below) (Eggers et al., 1984). Conversely, some monkeys, found to be amblyopic after being raised with unilateral instillation of atropine in an earlier simulation of anisometropia, did not show the eye-dominance shift evident in this group of anisometropes (Movshon et al., 1987).

Perhaps a more informative indicator of the change in the cortical representation of the amblyopic eye is the proportion of units that responded at all to stimulation of that eye. In normal monkeys, $84 \%$ of units responded to stimulation of the contralateral eye.

In the three strabismic monkeys, the fraction of units responding to the treated eye ranged from 57 to $67 \%$. In the three anisometropes, this fraction was between 40 and $59 \%$. Thus, in both groups of amblyopes, the combination of reduced binocular interaction and shifted-eye dominance substantially reduced the representation of the input of the amblyopic eye across the cortical neuron population.

To compare these eye-dominance distributions with behavioral sensitivity losses, Figure 4 plots the proportion of units in each monkey dominated by the amblyopic eye (i.e., the total units in eye-dominance groups 1-3 plus half of those in group 4, as a fraction of the total) against the amblyopia index described above. In Figure 4, circles indicate animals in the two experimental groups, and crosses indicate data from three strabismic animals not otherwise described in this paper; these monkeys were tested behaviorally, allowing calculation of the amblyopia index, and their cortical eye dominance was assessed in connection with a separate series of anatomical experiments (Fenstemaker et al., 1997). Figure 4 reveals that some animals had substantial degrees of amblyopia even when the amblyopic eye dominated a normal proportion of cortical units. There was, however, a covariation between cortical eye dominance and amblyopia; the most severely amblyopic animals had the smallest fraction of units dominated by the amblyopic eye. Finally, although the data shown in Figure 3 give the impression that anisometropes and strabismics showed characteristic differences in cortical eye dominance, including the

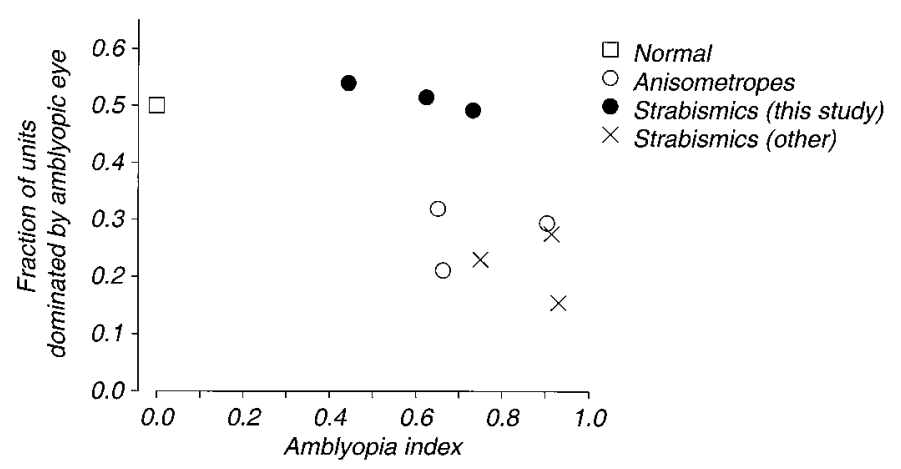

Figure 4. The proportion of units dominated by the amblyopic eye is plotted against an amblyopia index (a measure of the severity of amblyopia that is described earlier). The normal situation is indicated by the open square; the value of the amblyopia index for three normal monkeys was $0.024,0.061$, and 0.074 . Data from the strabismic monkeys in this study are shown by filled circles; data from anisometropic monkeys are shown by open circles. Also included are data from three more profoundly amblyopic monkeys in which we measured cortical eye dominance (crosses) (Fenstemaker et al., 1997). Substantial amblyopia can evidently occur with or without a shift in cortical eye dominance, but the most severe amblyopes experienced a loss of effective input from the amblyopic eye.

three additional animals (all strabismics with substantial shifts in cortical eye dominance away from the amblyopic eye) (Fig. 4, crosses), reveals that all the amblyopes of either etiology seem to lie on a continuum.

\section{Spatial properties and contrast sensitivity of cortical neurons}

We wished to know how the losses in spatial resolution and contrast sensitivity seen behaviorally (Fig. 1) were reflected in the properties of visual neurons. We and others have shown previously that the spatial properties of afferent neurons in the lateral geniculate nucleus are little affected, even by complete visual deprivation (Blakemore and Vital-Durand, 1986; Levitt et al., 1989). We therefore chose to study the properties of neurons in the visual cortex.

We made quantitative measurements of orientation, spatial, temporal frequency tuning, and contrast response in 131 neurons from five monkeys. Figure 5 shows quantitative data obtained from both eyes for a binocularly activated unit recorded in an anisometropic monkey (OC). Each panel in Figure 5 plots the response for the amblyopic eye with open symbols and the response for the nonamblyopic eye with filled symbols. Apart from the obvious fact that this particular neuron responded more vigorously to stimulation of the nonamblyopic eye, its properties were similar when tested in either eye with respect to orientation and direction selectivity, temporal frequency tuning, and contrast response (Fig. 5A, $C, D$ ). There was, however, a distinct difference in the spatial frequency tuning measured through the two eyes (Fig. $5 B$ ). When tested through the nonamblyopic eye, the best response of the unit was obtained for gratings of $3 \mathrm{c} / \mathrm{deg}$, and the spatial resolution was $\sim 8 \mathrm{c} / \mathrm{deg}$. Tested through the amblyopic eye, the preferred spatial frequency was $\sim 1 \mathrm{c} / \mathrm{deg}$, the spatial resolution was $\sim 4 \mathrm{c} / \mathrm{deg}$. We observed this pattern of interocular difference in spatial tuning, favoring the nonamblyopic eye, in most of the eight cases in which we tested units binocularly with quantitative methods; this was true for units regardless of whether the amblyopic or the nonamblyopic eye generated stronger responses.

Although we occasionally encountered and quantitatively 

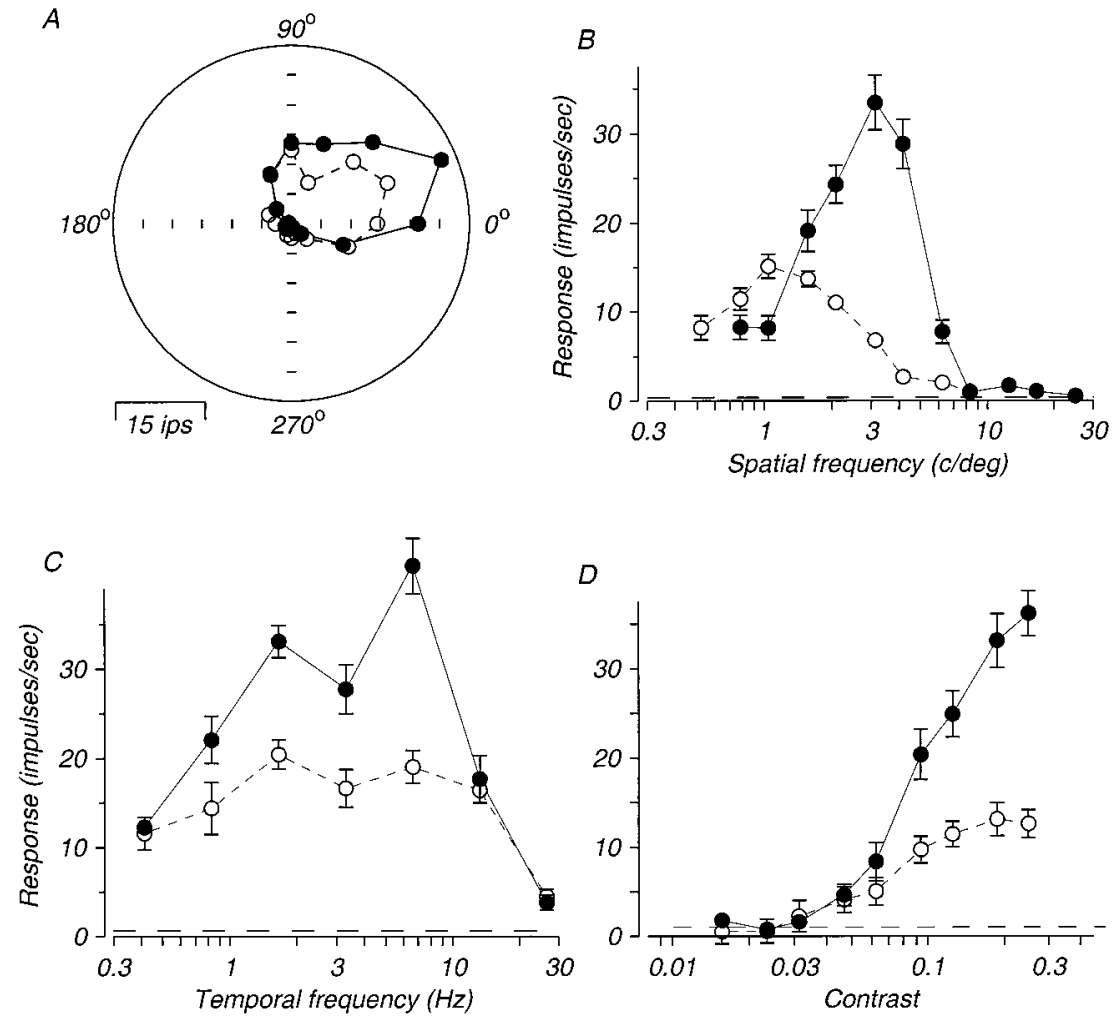

Figure 5. Data from a complex cell recorded in an anisometropic monkey (OC). For this binocularly activated unit, quantitative data were measured with stimulation of each eye. Data taken through the amblyopic eye are shown by open symbols, and data taken from the nonamblyopic eye are shown by filled symbols. A, Orientation and direction selectivity measured with highcontrast drifting gratings whose orientation was orthogonal to the direction plotted; the spatial and temporal frequencies were optimal for the eye being tested. $B$, Spatial frequency tuning measured with high-contrast gratings of optimal orientation, direction, and temporal frequency. $C$, Temporal frequency tuning measured with high-contrast gratings of optimal orientation and spatial frequency. $D$, Contrast response measured with gratings of optimal orientation and spatial and temporal frequency. Error bars indicate SE of the mean spike count per stimulus cycle. Dashed lines indicate spontaneous activity. tested binocularly driven units like the one shown in Figure 5, most of our data came from units that strongly preferred one eye or the other (Fig. 3). Our main conclusions are therefore based on population comparisons rather than cases like the one in Figure 5. Quantitative tests of such populations did not reveal decisive differences between the amblyopic and nonamblyopic eyes with respect to response magnitude, orientation, direction, spatial or temporal tuning, or contrast response. Because our quantitative data came from a relatively small subpopulation of the recorded neurons, this is not particularly surprising. In fact, our main rationale for collecting quantitative data was to provide independent verification of the accuracy of measurements made with qualitative techniques.

For all 797 recording sites (isolated neurons and multiunit sites), we made qualitative assessments by listening to the unit response over the audiomonitor while we adjusted the parameters of the grating being displayed. From this qualitative assessment, we established orientation preference and selectivity, optimal spatial frequency and spatial resolution, optimal temporal frequency, and threshold contrast for an optimal grating; we also rated the responsiveness of the cells. For the 131 cases tested quantitatively, we were able to compare the two sets of measurements. In general, the validations were excellent. For the key parameters of optimal orientation and direction, optimal spatial frequency, optimal temporal frequency, and contrast threshold, the correlations between qualitative and quantitative measures were between 0.54 and 0.96 ; in no case was the slope of the relationship between measures significantly different from 1 . For spatial frequency, temporal frequency, and contrast measures, the difference between qualitative and quantitative measures rarely exceeded a factor of 2 and was typically much less. We observed the lowest correlation when comparing contrast thresholds judged by ear with those established using a quantitative statistical technique (Tolhurst et al., 1983; Levitt et al., 1994); we also found this judgment to be the most difficult to make reliably, as well as to be the one on which multiple qualitative observers had the most difficulty agreeing.

Using the qualitative data, we compared the properties of units driven by the two eyes. In most respects, the populations did not differ significantly. Units driven by the amblyopic and nonamblyopic eyes were indistinguishable in all six animals with respect to their responsiveness to optimal visual stimuli, frequency and degree of their orientation and direction selectivity, and their preference for temporal frequency. Because amblyopia is a disorder of spatial vision, we suspected that comparisons of the spatial tuning properties of neurons in the two eyes might be more informative.

Figures 6 and 7 summarize our data on the spatial frequency tuning and contrast sensitivity of units from the strabismic and anisometropic monkeys. In Figures 6-8, data in red relate to the amblyopic eye, and data in green relate to the nonamblyopic eye. The data in these figures are presented in the same order as they were in Figure 1, so that the least severe amblyope in each group is at the top and the most severe is at the bottom. The scattergrams in Figures $6 A, 7 A$, and $8 A$ display the locations of the peaks of the spatial frequency tuning for all units; note that the axes are isomorphic to those used for the behavioral data in Figure 1. The distributions in Figures $6 B, 7 B$, and $8 B$ show frequency histograms for each of the parameters shown, as well as for spatial resolution. It is evident that the spatial and sensitivity properties of neurons in all monkeys are quite widely dispersed, with all parameters showing at least a 10 -fold range of variation; this is not different from previous reports in normal monkeys (e.g., DeValois et al., 1982) and from our own unpublished observations.

Within this variation, however, it is possible to discern interocular differences that seem to be related to each animal's depth of amblyopia. Strabismic monkeys GH and HC (Fig. 6) and aniso 

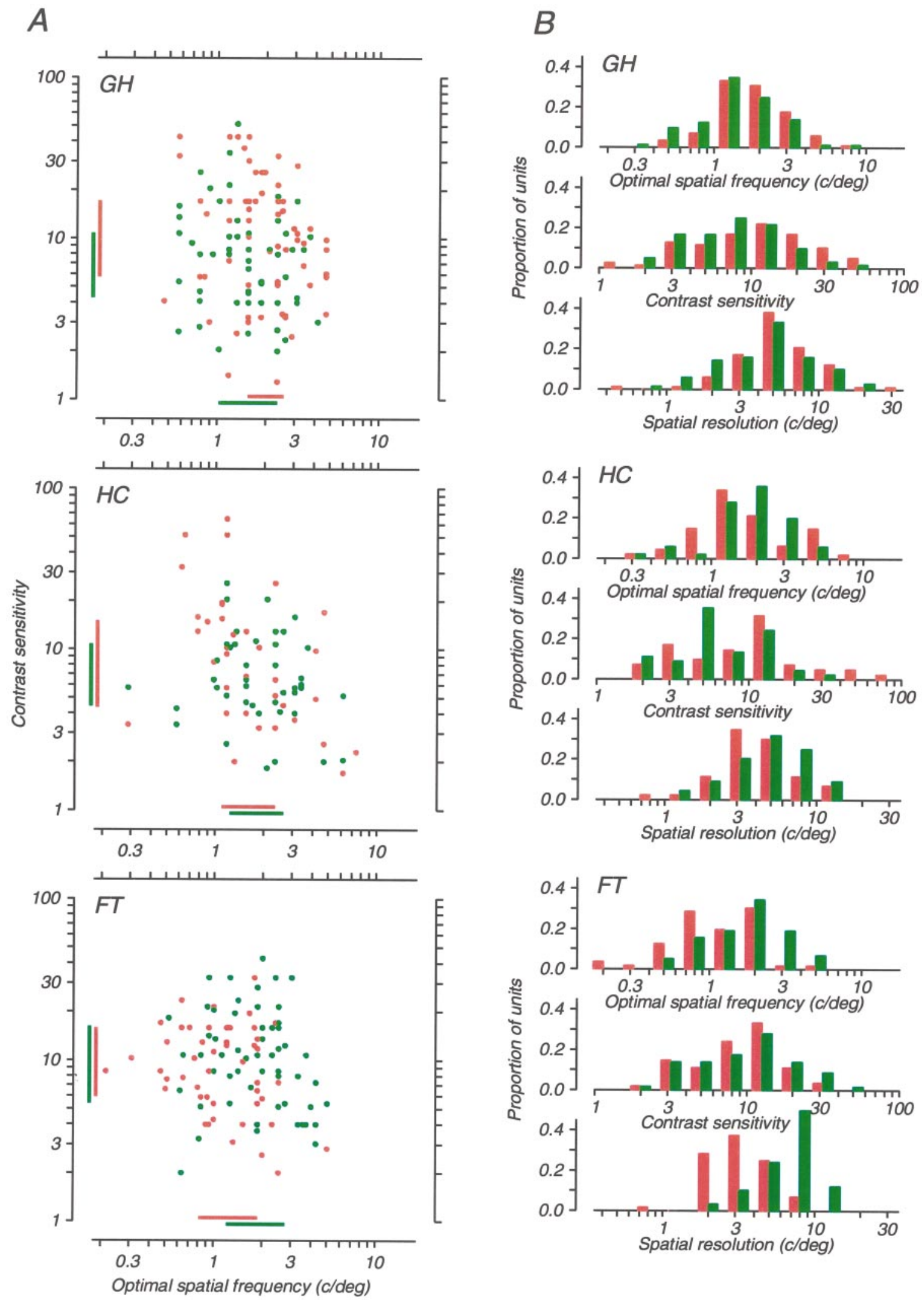

Figure 6. Spatial frequency tuning and contrast sensitivity data for neurons recorded from the three strabismic monkeys. Data for the amblyopic eye are shown in red, and data for the nonamblyopic eye are shown in green. $A$, Scatter diagrams in which each neuron is represented by a point plotted at its optimal spatial frequency and contrast sensitivity (i.e., the inverse of its threshold contrast). Bars on the abscissa and ordinate indicate the interquartile ranges (i.e., the bounds of the central $50 \%$ of the observed values) for each eye. $B$, Distributions of optimal spatial frequency, contrast sensitivity, and spatial resolution for neurons tested through each eye. The boundary between adjacent pairs of bins represents the center of the class interval. The three monkeys' data are ordered vertically in the same way as in Figure $1 B$. For monkey FT, only data obtained from foveal recordings are included. 
A
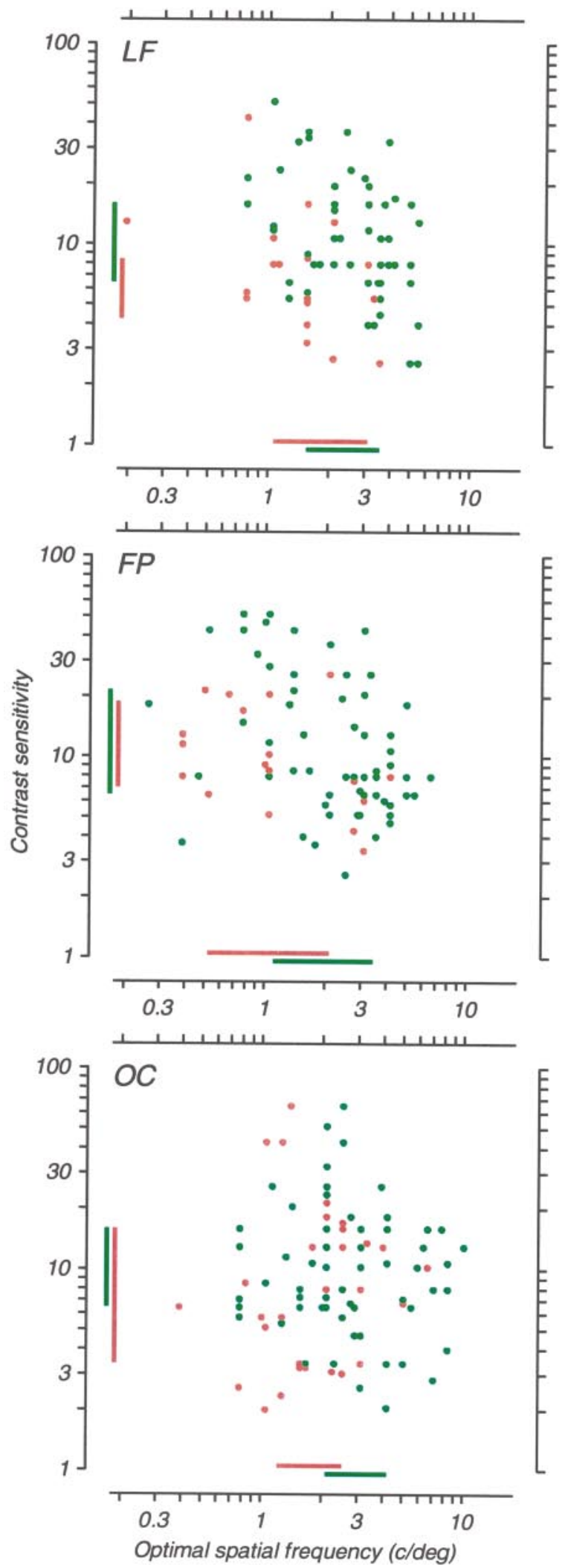

B
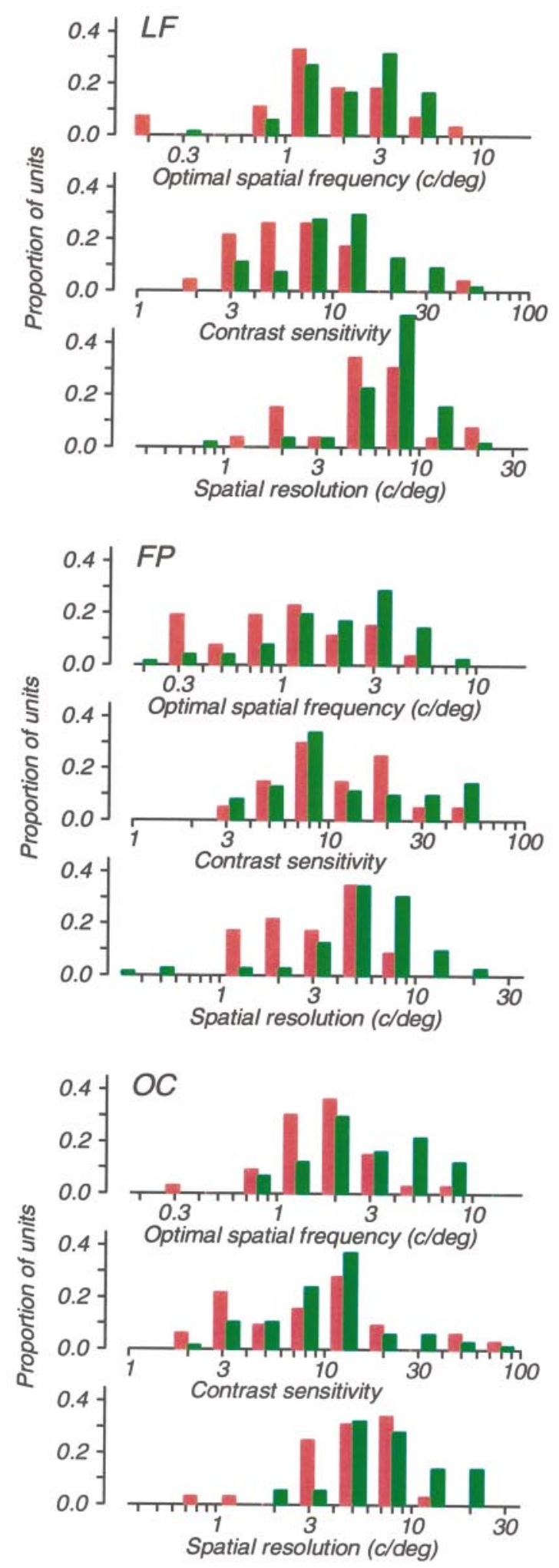

Figure 7. Spatial frequency tuning and contrast sensitivity data for neurons recorded from the three anisometropic monkeys. Data for the amblyopic eye are shown in red, and data for the nonamblyopic eye are shown in green; the format is identical to Figure 6 . The three monkeys' data are ordered vertically in the same way as in Figure $1 C$. For monkey FP, 35 units recorded in V2 are included; these were statistically indistinguishable in their properties from the 67 other units recorded from V1. 

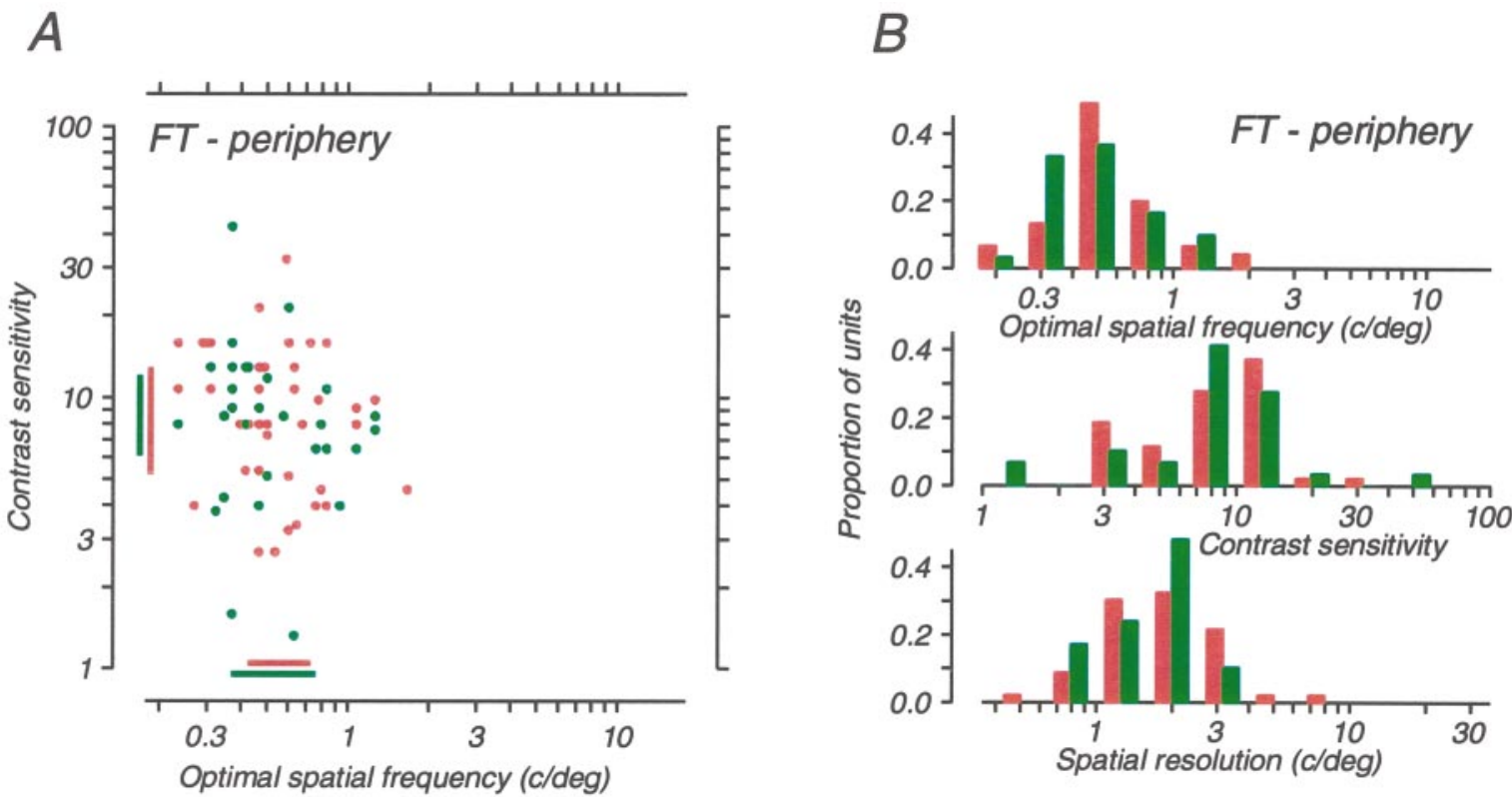

Figure 8. Diagrams in the format of Figure 6 and 7 representing data from units recorded in strabismic monkey FT from the representation of the peripheral visual field in V1. The receptive fields of these units were located in the lower visual quadrant, between 16 and $23^{\circ}$ from the fovea.

metropic monkey LF (Fig. 7) whose amblyopias were the most modest, showed only subtle interocular differences for any of the reported measures. For monkey GH, only the interocular difference in contrast sensitivity achieved statistical significance $(t$ test; $p<0.01$ ), and this difference was in the "wrong" direction, with units in the amblyopic eye being more sensitive. For monkey HC, none of the interocular differences was significant. For monkey $\mathrm{LF}$, the interocular difference in contrast sensitivity was significant ( $t$ test; $p<0.01)$ and in the "correct" direction, with the amblyopic eye showing lower sensitivity. But the differences in optimal spatial frequency and resolution were not significant.

Consider now the three most severely amblyopic cases: strabismic monkey FT (Fig. 6) and anisometropic monkeys FP and OC (Fig. 7). In all three of these cases, the interocular differences in both spatial resolution and optimal spatial frequency were large, robust ( $t$ test; $p<0.001$ in all cases), and in the direction expected; the spatial performance of the amblyopic eye was inferior to that of the nonamblyopic eye. Curiously, in none of these cases was the interocular difference in contrast sensitivity significant.

In humans, strabismic amblyopia is primarily a deficit of central vision (Sireteanu et al., 1981; Hess and Pointer, 1985). We have also found this to be true in some, but not all, monkey amblyopes (L. Kiorpes and D.C. Kiper, unpublished observations). To explore the neural basis of this variation with visual field location, we studied the properties of 76 units from the representation of the peripheral visual field in FT, the most severely affected of our three strabismic amblyopes. The receptive fields of the neurons were located in the inferior quadrant, between 16 and $23^{\circ}$ from the fovea. Data from this peripheral sample are shown in Figure 8, using the same format as in Figures 6 and 7. This monkey's foveal data showed clear interocular differences in spatial resolution and optimum frequency (Fig. 6), but the data from the periphery show no interocular difference; none of the three pairs of distributions in Figure $8 B$ differs significantly.

To compare the physiological data presented in Figures 6 and
7 with the behavioral measurements in Figure 1, in Figure 9 we plot the amblyopia index against a measure of the interocular difference in three spatial properties for each of the experimental monkeys. As in Figure 4, filled circles represent data from strabismics and open circles represent data from anisometropes. The ordinate in each panel is the ratio of the geometric mean values of the distributions shown in Figures $6 B$ and $7 B$, with the value for the amblyopic eye in the denominator. In accordance with the impression derived from Figures 6 and 7, there was a reasonably clear relationship between the amblyopia index and the interocular ratios of spatial resolution and optimal frequency (Fig. 9, top two panels). There was, however, no clear relationship between the interocular ratios of contrast sensitivity and the depth of an animal's amblyopia (Fig. 9, bottom panel).

The analysis in Figure 9 suggests a correlation between physiological measures of spatial vision and the depth of an animal's amblyopia. Figure 10 poses the question of whether this relationship is quantitatively precise. The ratio of the geometric means of the physiological measures is plotted again on the ordinate of each panel in Figure 10; the abscissa now shows the interocular ratio of the homologous psychophysical measure derived from the curves fitted to the spatial contrast sensitivity data in Figure 1. If the interocular differences in physiological properties documented in Figures 6 and 7 represented a perfect quantitative correlate of the behavioral changes shown in Figure 1, then these ratios should be exactly proportional, and the data for the six animals should lie along a diagonal of unit slope. It is evident instead that for both of the spatial measures (Fig. 10, top two panels), the physiological ratios were related to, but consistently smaller than, the psychophysical ratios; the bottom panel in Figure 10 reveals no clear relationship between interocular ratios of contrast sensitivity determined psychophysically and physiologically. For spatial resolution and peak contrast sensitivity (Fig. 10, top and bottom panels), all six animals showed a smaller ratio of physiological than psychophysical values; this difference is significant in each case (binomial sign test, $p=0.016$ ). The comparison 

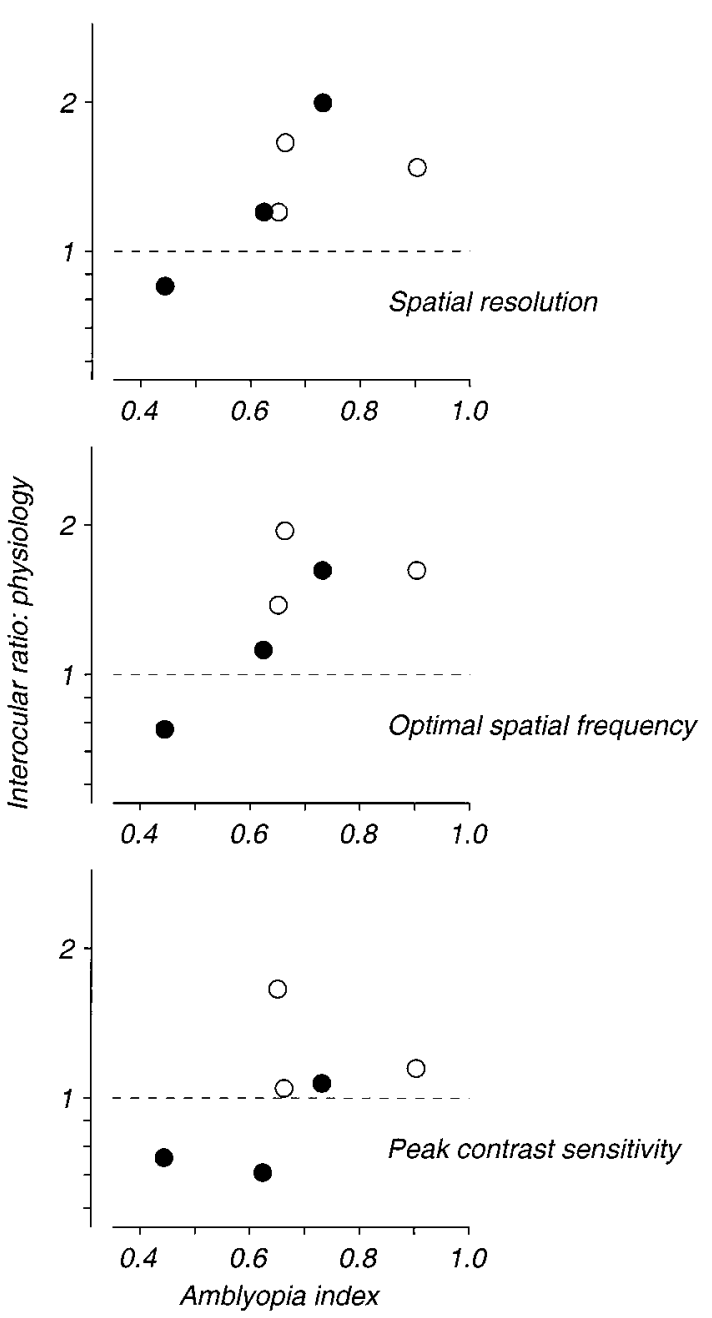

Figure 9. A comparison of interocular differences in spatial frequency tuning and contrast sensitivity with the severity of amblyopia. Filled symbols indicate data from the strabismic monkeys, and open symbols indicate data from the anisometropic monkeys. The ordinate in each plot is the ratio of the geometric population means of the values of the listed parameter for units tested through each of the eyes, with data from the nonamblyopic eye placed in the numerator.

for optimal spatial frequency (Fig. 10, middle panel) eludes significance only because one monkey's data fall slightly above the diagonal.

\section{DISCUSSION}

The results of these experiments show that experimental amblyopia produces a number of changes in the properties of neurons in the visual cortex. Moreover, the changes we observed depended in an orderly way on the severity of the amblyopia measured behaviorally. All amblyopic animals showed a substantial reduction in cortical binocularity, with strabismics having the smallest number of binocularly activated neurons; more severely affected animals also showed a shift in cortical eye dominance away from the amblyopic eye and significant differences in the spatial properties of cortical neurons driven by the two eyes. The particular method used to create amblyopia (strabismus or anisometropia) did not lead to obviously different results. Thus, it is the severity, not the etiology, of the visual losses that seems related to the nature of the physiological changes we found.
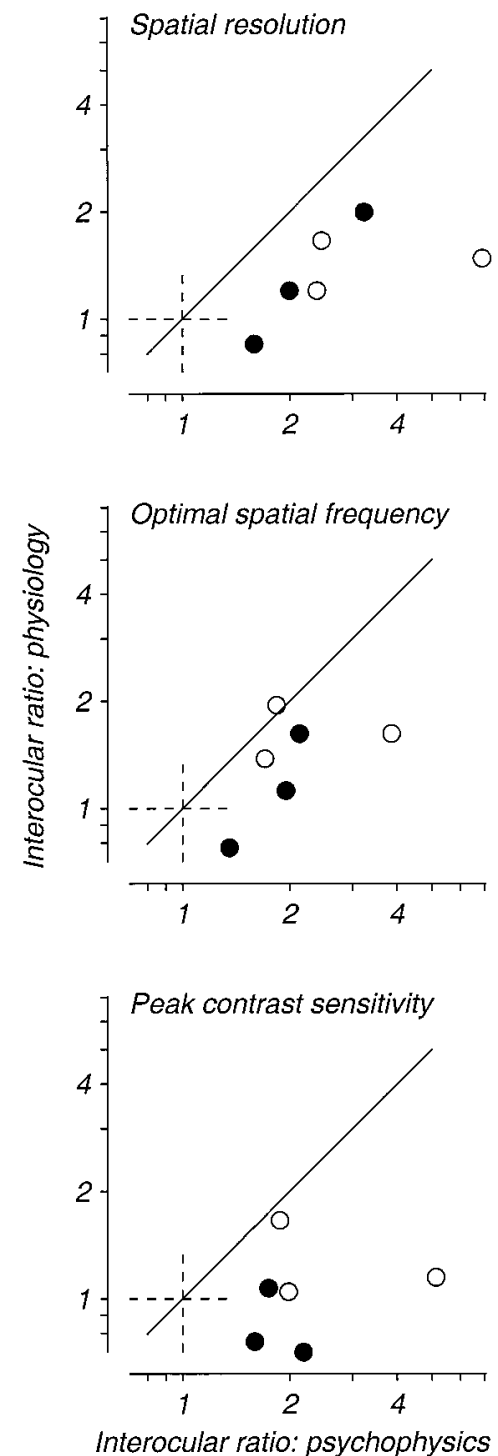

Figure 10. A comparison of behavioral and neurophysiological assessments of interocular differences in spatial frequency selectivity and contrast sensitivity. The ordinate of each graph plots the same ratio of population geometric means shown on the ordinate of Figure 9. The abscissa indicates the ratio of the same values from the behavioral measurements of spatial contrast sensitivity shown in Figure 1.

These results are in good agreement with our previous studies on monkeys raised with unilateral atropinization to create unilateral blur. In these animals, moderate amblyopia was also accompanied by differences in the spatial properties of neurons driven by the two eyes, as well as by a loss of binocularity and (in some cases) a shift in cortical eye dominance toward the untreated eye (Kiorpes et al., 1987; Movshon et al., 1987). Interestingly, the shift in eye dominance in these animals was apparently only among neurons preferring high spatial frequencies, and ocular dominance was more balanced among neurons preferring low spatial frequencies. This trend was evident in the anisometropic, but not the strabismic, amblyopes in the present study. Our eye-dominance data may appear to be at odds with earlier data from strabismic monkeys (Baker et al., 1974; Crawford and von Noorden, 1979), which show a complete shift of eye dominance 
away from the deviating eye. However, the monkeys in those studies had very poor acuity in their deviating eye, which was comparable with acuity in monocularly deprived animals in most cases. Their results represent the extreme of the continuum and are thus not out of line with the results presented here (Fig. 4).

The literature on human amblyopia suggests that strabismic and anisometropic amblyopes differ in their visual capacities. Anisometropic amblyopes appear to show contrast sensitivity deficits over a wide range of visual field locations, whereas the deficits of the strabismic amblyopes are confined to the central visual field (Hess et al., 1980; Sireteanu et al., 1981; Hess and Pointer, 1985; but see Sireteanu and Fronius, 1990). Furthermore, strabismic amblyopes have been reported to have severe deficits in positional acuity, whereas the deficits of anisometropic amblyopes are comparatively mild (Levi and Klein, 1982; Hess and Holliday, 1992; but see McKee et al., 1992; Kiorpes and Movshon, 1996). We have not, however, been able to discern consistent differences between these two types of amblyopia in monkeys (Kiorpes et al., 1993; Kiorpes and Movshon, 1996). Our main concern in this paper is with spatial resolution and contrast sensitivity; behaviorally, we find a wholly overlapping range of contrast sensitivity deficits among our anisometropic and strabismic amblyopes. Thus, it is not surprising that we find similar physiological deficits in spatial resolution and contrast sensitivity in these two populations.

Of course, there may be differences between strabismic and anisometropic amblyopia that are not reflected in the kinds of measurements we made in this study. It is, however, important to note that the classification of human amblyopes is typically based on the presence of strabismus or anisometropia at the time of clinical evaluation or psychophysical testing, whereas our classification is based on the particular visual abnormality that we created in early life. The difference is important because both strabismus and anisometropia can develop in amblyopes after the end of the critical period. For example, anisometropic monkey LF in this study became strabismic after the period of lensrearing had ended, and strabismic monkey FT became mildly anisometropic (1.0 diopter) after an extended period of amblyopia (Kiorpes and Wallman, 1995). These monkeys might all have been classified as strabismic and anisometropic had they first been studied in maturity. However, within the limits of our measurements, we are confident that none of these monkeys was both strabismic and anisometropic during the first postnatal year, which represents the primary period of spatial visual development in monkeys (Kiorpes, 1992a; Boothe et al., 1989).

\section{Mechanisms of developmental abnormality in amblyopia}

It is widely believed that cortical neurons respond adaptively to the visual environment during early development, in the sense that activity-dependent mechanisms of plasticity act to bring the selectivity of cortical neuron responses into a rough match with the visual input received in early life (see Daw, 1995; Katz and Shatz, 1996). In accordance with this idea, some of the physiological manifestations of amblyopia seem to be clearly related to the factors that created the condition. For example, it is intuitively reasonable for strabismic animals to lose binocularity; strabismus abolishes correlated visual experience at corresponding locations in the two eyes, and it has long been accepted that this decorrelation could change cortical binocular interaction by any of several activity-dependent mechanisms (e.g., Hubel and Wiesel, 1965). It is also relatively easy to understand how persistent retinal image blur in one eye might represent a form of visual deprivation for neurons that respond to high spatial frequencies, because effective retinal image contrast is sharply reduced at those frequencies. By analogy with the response of the visual system to more severe forms of deprivation (Wiesel and Hubel, 1965), the reduction in effective stimulation might prevent the development of highfrequency neurons. This could happen either because these neurons were in effect monocularly deprived and adaptively selected their inputs from the untreated eye, or because the lack of stimulation prevented them from developing their full spatial resolving power, sensitivity, and selectivity. Our data do not allow us to distinguish between these two possibilities.

On the other hand, some of the cortical changes in amblyopia seem quite puzzling. There is no obvious reason why neurons driven by the amblyopic eye in some strabismic amblyopes should have degraded spatial properties. These neurons should have been exposed to reasonably clear retinal images throughout early development and would therefore appear to have no reason to fail to develop normal spatial properties. It is also unclear why anisometropic animals should show such a stark reduction in cortical binocularity. The alignment of the eyes was not discernibly affected by the contact lenses and was well enough preserved during rearing that corresponding retinal points should have received correlated visual inputs, at least at low spatial frequencies, providing binocular stimulation. Yet the proportion of binocularly driven units was similar among neurons preferring low and high spatial frequencies for both strabismic and anisometropic monkeys; this is consistent with our previous results of amblyopia following unilateral atropinization (Movshon et al., 1987). However, it should be noted that our tests would not have detected the residual binocular interactions demonstrated by simultaneous binocular stimulation in strabismic and anisometropic monkeys by Smith et al. (1997).

\section{The physiological basis for amblyopia?}

Our goal is to understand the biological basis of amblyopia. Because amblyopia is a disorder of spatial vision, we concentrated our efforts on measuring and comparing the spatial properties of cortical neurons driven by the two eyes. In the more severely affected amblyopes, we found clear interocular differences in spatial resolution that could, in principle, explain the visual deficit in amblyopes (Fig. 9). Yet quantitative analysis shows that this effect is probably an incomplete explanation of the deficits shown behaviorally. Figure 10 compares the interocular differences in behavioral and physiological measures of optimal spatial frequency, spatial resolution, and contrast sensitivity. If the physiological differences were to account for the whole of the amblyopic loss, these differences should have been equal. Instead, in nearly all cases, the magnitude of the physiological differences was less than those found behaviorally. This is clearly manifested in the fact that many cortical neurons driven through the amblyopic eyes of the more severely affected monkeys responded to spatial frequencies that the animals could not see. For example, a comparison of Figure 1 with Figures 6 and 7 shows that in monkeys FT, FP, and OC, we recorded significant numbers of neurons driven by the amblyopic eye whose spatial resolution exceeded the animal's spatial resolution; we almost never encountered such neurons driven by the nonamblyopic eye.

It is also notable that we failed to detect reliable differences in the contrast sensitivity of neurons driven by the two eyes despite 
the substantial differences in contrast sensitivity measured behaviorally (compare Fig. 1 with Figs. 6 and 7). As noted in Results, it is conceivable that our measurements of contrast sensitivity were not sufficiently precise to detect a subtle difference between the two eyes. Although we measured no difference in the absolute responsiveness of neurons driven by the two eyes, it is also possible that the interocular differences in behavioral contrast sensitivity are explained by the reduced number of neurons driven by the amblyopic eye.

Together, these considerations suggest that the changes we have observed represent only a partial explanation of the visual losses in amblyopia and that some additional factors must be involved. Although it has been suggested that abnormalities in the pattern of correlated firing among striate cortical neurons driven by the amblyopic eye might cause amblyopia (Roelfsema et al., 1994), it seems equally reasonable to suppose that some aspects of amblyopia reflect changes in the properties of cortical neurons at processing stages beyond the primary visual cortex. For example, amblyopes may show abnormalities in long-range feature-linking tasks that seem unlikely to be subserved by striate cortical neurons alone (Hess et al., 1997; but see Levi and Sharma, 1998). A full explanation of the amblyopic deficit should therefore be cast in terms of a cascade of deficits in several processing areas of the cerebral cortex. The effects we have observed in striate cortex represent only the first stage of that cascade.

\section{REFERENCES}

Baker FH, Grigg P, von Noorden GK (1974) Effects of visual deprivation and strabismus on the response of neurons in the visual cortex of the monkey, including studies of striate and prestriate cortex in the normal animal. Brain Res 66:185-208.

Blakemore C, Vital-Durand F (1986) Effects of visual deprivation of the development of the monkey's lateral geniculate nucleus. J Physiol (Lond) 380:493-511.

Boothe RG, Kiorpes L, Williams RA, Teller DY (1989) Operant measurements of contrast sensitivity in infant macaque monkeys during normal development. Vision Res 28:387-396.

Crawford ML, Harwerth RS, Chino YM, Smith EL (1996) Binocularity in prism-reared monkeys. Eye 10:161-166.

Crawford MLJ, von Noorden GK (1979) The effects of short-term experimental strabismus on the visual system in Macaca mulatta. Invest Ophthalmol Vis Sci 18:496-505.

Daw NW (1995) Visual development. New York: Plenum.

DeValois RL, Albrecht DG, Thorell LG (1982) Spatial frequency selectivity of cells in macaque visual cortex. Vision Res 22:545-559.

Eggers HM, Gizzi MS, Movshon JA (1984) Spatial properties of striate cortical neurons in esotropic macaques. Invest Ophthalmol Vis Sci 25:S278.

Fenstemaker SB, Aoki C, Kiorpes L, Movshon JA (1994) Chemoarchitectonic alterations in primary visual cortex of strabismic monkeys. Soc Neurosci Abstr 320:626.

Fenstemaker SB, George KH, Kiorpes L, Movshon JA (1997) Tangential organization of eye dominance in area V1 of macaques with strabismic amblyopia. Soc Neurosci Abstr 323:2363.

Finney DJ (1971) Probit analysis. Cambridge, England: Cambridge UP.

Harwerth RS, Smith EL, Boltz RL, Crawford MLJ, von Noorden GK (1983) Behavioral studies on the effect of abnormal early visual experience: spatial modulation sensitivity. Vision Res 23:1501-1510.

Hendrickson AE, Movshon JA, Eggers HM, Gizzi MS, Boothe RG, Kiorpes L (1987) Effects of early unilateral blur on the macaque's visual system. II. Anatomical observations. J Neurosci 7:1327-1339.

Hess RF, Holliday IE (1992) The spatial localization deficit in amblyopia. Vision Res 32:1319-1339.

Hess RF, Pointer JS (1985) Differences in the neural basis of human amblyopias: the distribution of the anomaly across the visual field. Vision Res 25:1577-1594.

Hess RF, Campbell FW, Greenhalgh T (1978) On the nature of the neural abnormality in human amblyopia: neural aberrations and neural sensitivity loss. Pflügers Arch 377:201-207.
Hess RF, Campbell FW, Zimmern R (1980) Differences in the neural basis of human amblyopias: the effect of mean luminance. Vision Res 20:295-305.

Hess RF, McIlhagga W, Field DJ (1997) Contour integration in strabismic amblyopia: the sufficiency of an explanation based on position uncertainty. Vision Res 37:3145-3161.

Hubel DH, Wiesel TN (1962) Receptive fields, binocular interaction, and functional architecture in the cat's visual cortex. J Physiol (Lond) 160:106-154.

Hubel DH, Wiesel TN (1965) Binocular interaction in striate cortex of kittens reared with artificial squint. J Neurophysiol 28:1041-1059.

Hubel DH, Wiesel TN (1968) Receptive fields and functional architecture of monkey striate cortex. J Physiol (Lond) 195:215-243.

Katz LC, Shatz CJ (1996) Synaptic activity and the construction of cortical circuits. Science 274:1133-1138.

Kiorpes L (1992a) Development of vernier acuity and grating acuity in normally reared monkeys. Vis Neurosci 9:243-251.

Kiorpes L (1992b) Effect of strabismus on the development of vernier acuity and grating acuity in monkeys. Vis Neurosci 9:253-259.

Kiorpes L, Boothe RG (1984) Accommodative range in amblyopic monkeys. Vision Res 24:1829-1834.

Kiorpes L, Movshon JA (1990) Behavioral analysis of visual development. In: Development of sensory systems in mammals (Coleman JR, ed), pp 125-154. New York: Wiley.

Kiorpes L, Movshon JA (1996) Amblyopia: a developmental disorder of the central visual pathways. Cold Spring Harb Symp Quant Biol 61:39-48.

Kiorpes L, Wallman J (1995) Does experimentally induced amblyopia cause hyperopia in monkeys? Vision Res 35:1289-1297.

Kiorpes L, Boothe RG, Hendrickson AE, Movshon JA, Eggers HM, Gizzi MS (1987) Effects of early unilateral blur on the macaque's visual system. I. Behavioral observations. J Neurosci 7:1318-1326.

Kiorpes L, Carlson MR, Alfi D (1989) Development of visual acuity in experimentally strabismic monkeys. Clin Vision Sci 4:95-106.

Kiorpes L, Kiper DC, Movshon JA (1993) Contrast sensitivity and vernier acuity in amblyopic monkeys. Vision Res 33:2301-2311.

Kiper DC (1994) Spatial phase discrimination in monkeys with experimental strabismus. Vision Res 34:437-447.

Kiper DC, Kiorpes L (1994) Suprathreshold contrast sensitivity in experimentally strabismic monkeys. Vision Res 34:1575-1583.

Kiper DC, Gegenfurtner KR, Kiorpes L (1995) Spatial frequency channels in experimentally strabismic monkeys revealed by oblique masking. Vision Res 35:2737-2742.

Levi DM, Carkeet A (1993) Amblyopia: a consequence of abnormal visual development. In: Early visual development: normal and abnormal (Simons K, ed), pp 391-408. New York: Oxford UP.

Levi DM, Klein SA (1982) Hyperacuity and amblyopia. Nature 298:268-270.

Levi DM, Sharma V (1998) Integration of local orientation in strabismic amblyopia. Vision Res 38:775-781.

Levitt JB, Movshon JA, Sherman SM, Spear PD (1989) Effects of monocular deprivation on macaque LGN. Invest Ophthalmol Vis Sci 30:S296.

Levitt JB, Kiper DC, Movshon JA (1994) Receptive fields and functional architecture of macaque V2. J Neurophysiol 71:2517-2542.

McKee SP, Schor CM, Steinman SB, Wilson N, Koch GG, Davis SM, Hsu-Winges C, Day SH, Chan CL, Movshon JA, Flom MC, Levi DM, Flynn JT (1992) The classification of amblyopia on the basis of visual and oculomotor performance. Trans Am Ophthalmol Soc 90:123-148.

Merrill EG, Ainsworth A (1972) Glass-coated platinum-plated microelectrodes. Med Biol Eng 10:662-671.

Movshon JA, Kiorpes L (1990) The role of experience in visual development. In: Development of sensory systems in mammals (Coleman JR, ed), pp 155-202. New York: Wiley.

Movshon JA, Van Sluyters RC (1981) Visual neural development. Annu Rev Psychol 32:477-522.

Movshon JA, Eggers HM, Gizzi MS, Hendrickson A, Kiorpes L, Boothe RG (1987) Effects of early unilateral blur on the macaque's visual system: III. Physiological observations. J Neurosci 7:1340-1351.

Movshon JA, McKee SP, Levi DM (1996) Visual acuity in a large population of normal, strabismic, and anisometropic observers. Invest Ophthalmol Vis Sci 37:S670.

Roelfsema PR, König P, Engel AK, Sireteanu R, Singer W (1994) Reduced synchronization in the visual cortex of cats with strabismic amblyopia. Eur J Neurosci 6:1645-1655. 
Sireteanu R, Fronius M (1990) Human amblyopia: structure of the visual field. Exp Brain Res 79:603-614.

Sireteanu R, Fronius M, Singer W (1981) Binocular interaction in the peripheral visual field of humans with strabismic and anisometropic amblyopia. Vision Res 21:1065-1074.

Smith EL, Harwerth RS, Crawford MLJ (1985) Spatial contrast sensitivity deficits in monkeys produced by optically induced anisometropia. Invest Ophthalmol Vis Sci 26:330-342.

Smith EL, Chino YM, Ni J, Cheng H, Crawford MLJ, Harwerth RS (1997) Residual binocular interactions in the striate cortex of monkeys reared with abnormal binocular vision. J Neurophysiol 78:1353-1362.

Stryker MP, Sherk H (1975) Modification of cortical orientation selectivity in the cat by restricted visual experience: a reexamination. Science 190:904-906.

Tolhurst DJ, Movshon JA, Dean AF (1983) The statistical reliability of signals in single neurons in cat and monkey visual cortex. Vision Res 23:775-785.

Von Noorden GK (1980) Burian-Von Noorden's binocular vision and ocular motility. St Louis: Mosby.

Wiesel TN (1982) Postnatal development of the visual cortex and the influence of environment. Nature 299:583-591.

Wiesel TN, Hubel DH (1963) Single-cell responses in striate cortex of kittens deprived of vision in one eye. J Neurophysiol 26:1003-1017.

Wiesel TN, Hubel DH (1965) Comparison of the effects of unilatera and bilateral eye closure on cortical unit responses in kittens. J Neurophysiol 28:1029-1040.

Williams RA, Boothe RG, Kiorpes L, Teller DY (1981) Oblique effects in normally reared monkeys (Macaca nemestrina): meridional variations in contrast sensitivity measured with operant techniques. Vision Res 21:1253-1266. 